\title{
O FUTURO DA DERMATOLOGIA
}

\section{THE FUTURE OF DERMATOLOGY}

O presente que ora vivemos, fruto das incessantes e surpreendentes mudanças registadas nos planos social, financeiro, cultural e tecnológico, é fonte de preocupação para todos e justifica claramente um exercício de ponderação e análise sobre o nosso exercício profissional. Realizado individualmente, no remanso de cada consciência, é porém no plano colectivo, nos órgãos devidos (SPDV e Colégio da Especialidade da Ordem dos Médicos) que tal exercício assume a desejada e louvável dimensão da participação cívica. Nesse sentido, se deve entender a iniciativa de um painel de oradores ter abordado "O Futuro da Dermatologia" no decurso da Reunião da Primavera da SPDV do presente ano; com esse mesmo propósito, se deve compreender este editorial.

"L'avenir est la projection du passé, conditionnée par le présent" (Georges Braque)

\section{O QUE ESPERAR DO FUTURO?}

Primeiro, a Nova Medicina: será tecnológica, com recurso crescente a novas técnicas de genética molecular, imagiologia funcional e pesquisa translacional; verá uma expansão da Medicina Regenerativa; dará passos mais firmes na Medicina Personalizada (dimensões terapêutica, mas também preditiva na designada "Enhancement Medicine"); evoluirá no sentido de uma imparável hiperespecialização e consolidará de forma absoluta os recursos da era digital - Medicina Digital. No plano da análise metodológica, verificar-se-á o reforço da Medicina Baseada na Evidência, agora reforçada por poderosos "instrumentos informáticos da "era cognitiva", alegadamente capazes de potenciar o exercício diagnóstico, a gestão da incerteza e a colheita relevante de dados. No domínio do exercício, a Nova Medicina será fortemente parametrizada, balizada por resultados contabilizáveis, sustentada em "patometria ou clinimetria" exaustivas e associada a complexas exigências administrativas e burocráticas.

Depois, o inevitável enquadramento social "macro": A Nova Medicina será edificada no contexto do reconhecimento generalizado da insustentabilidade dos sistemas de saúde e da transferência crescente (entre nós) das responsabilidades do Estado para entidades privadas, público-privadas ou sector social, todas geridas de acordo com as boas práticas de gestão (privada). Neste domínio, expandir-se-ão as tecnoestruturas da Administração e Gestão dos sistemas de saúde, com a valoração progressiva de parâmetros como a gestão por objectivos, racionalização, optimização, indicadores, rankings, ratings, avaliação do custo-efectividade e fidelização; multiplicar-se-ão os gabinetes de gestão e tratamento da informação com recurso progressivo a charts, tendências, contabilidade criativa...; a Academia envolver-se-á em pesquisas incidindo na comparative effectiveness research e os media farão amplo eco desses dados...

No âmbito mais estrito da Dermatologia, que áreas poderão registar um incremento ou, pelo contrário, um retrocesso?

No contexto mais global da hiperespecialização da Nova Medicina, verificar-se-á o aparecimento de novas disciplinas assentes na complexidade técnica ou na novidade tecnológica (Medicina Regenerativa, por exemplo); enquanto isso, as especialidades tradicionais adaptar-se-ão: as especialidades assentes em técnicas, mais dependentes da incorporação da espuma de novas técnicas ou conceitos e as especialidades de órgão, com a necessidade de reforçar o núcleo de conhecimentos básicos e menos vulneráveis às novidades.

Uma preocupação constante é a preservação das fronteiras da nossa área de estudo e de intervenção. As ameaças de "usurpação" ocorrem num contexto de uma ambulatorização crescente da Especialidade, com um real downsizing do internamento hospitalar e consequente perda de áreas tradicionais da Especialidade como o Intensivismo e - Internismo dermatológicos (toxidermias graves, doenças de sistema com expressão dermatológica, infecções cutâneas graves, eritrodermias...) e uma perda de interesse, da nossa parte, por áreas tradicionais estruturantes da Dermatologia (dermatopatologia, micologia, alergologia cutânea, IST`s...). Têm como intérpretes profissionais não médicos de proveniência diversa ou mesmo Médicos de outras especialidades. Entre os não médicos, surpreende o número crescente de grupos profissionais que disputam a área cosmética recorrendo a técnicas cada vez mais invasivas perante - olhar complacente das entidades reguladoras e do Estado; entre os nossos Colegas, verifica-se a intrusão de especialidades generalistas no tratamento médico ou cirúrgico de entidades claramente dermatológicas. O panorama não é de molde a tranquilizar-nos neste domínio, já que se verifica à escala global uma crescente valoração dos designados 


\section{Editorial}

"non physician clinicians" no exercício autónomo diagnóstico e terapêutico, de múltiplas situações dermatológicas, classificada como genericamente positiva e merecendo mesmo a apreciação: "Nurse practicioners and Physician's assistants can do the same job as physicians for a fraction of the cost" (Kayser Permanente, 2005). Uma outra ameaça decorre do investimento progressivo nas "equipas de saúde" em detrimento do exercício médico individual, personalizado: muitas vezes em vez de se obter a almejada potenciação funcional traduzida no "skill mix", o que se verifica na realidade é uma perturbadora usurpação de tarefas e de competências - o designado "task shifting", que compromete a eficiência do sistema e prejudica, em última análise, o doente.

\section{QUAL DEVERÁ SER A PREPARAÇÃo MAIS ADE- QUADA DOS FUTUROS ESPECIALISTAS?}

Na Nova Medicina, o valor dos Médicos está ameaçado: Verificar-se-á (iá se verifica!) uma progressiva proletarização, traduzida num baixo estatuto remuneratório, na forte dependência das entidades pagadoras (estatuto de exclusividade crescentemente exigido, sem a necessária compensação) e no ocaso, por exaustão, do exercício da Medicina autónoma, dita de proximidade. Regista-se, por outro lado, uma redução real da autoritas do Médico nos domínios hierárquico, institucional, financeiro e administrativo (que não no da responsabilidade médico-legal!), de par com a sua anonimização, dado o ênfase crescente colocado na Equipa de Saúde e na Instituição. Pelo contrário, observa-se uma intrusão crescente de "economistas da saúde" na arena clínica, numa aparentemente incontornável metamorfose de uma cultura clínica para uma "cultura empresarial".

Neste quadro que se desenha, importa reforçar e consolidar as características identitárias da Especialidade, isto é, aquilo que nos torna únicos e essenciais: um "core knowledge" reforçado do órgão Pele, um investimento efectivo no estudo das ciências básicas, no método dermatológico e no treino iconográfico diagnóstico. Por outro lado, apostar num ensino e treino para apoio às unidades mais relevantes da Nova Medicina, em particular as unidades de Transplantes, de Oncologia Médica, de Cuidados Intensivos, de Urgência, de Infecciologia e de Medicina Regenerativa. Tem-se também como desejável o investimento formativo nas áreas de Alergologia dermatológica, Fotodermatologia, Dermatopatologia e Imunodermatologia; na Cirurgia dermatológica, incluindo a cirurgia micrográfica de Moh`s; na Oncologia Médica e Cirúrgica; nas Toxidermias - domínios diagnóstico e terapêutico; na Dermatologia Cosmética, médica e procedimental; finalmente, em áreas de crescente importância como a Gerontologia dermatológica e a cicatrização/reparação cutânea, a Psicodermatologia e a Neurodermatologia.

No plano da formação mais global, importará habilitar os futuros Especialistas: Inevitavelmente, com conhecimentos e treino de teledermatologia, de gestão do processo informático e administrativo, de codificação, de fármaco-economia e de patometria; Desejavelmente, com formação em Ética Médica, com conhecimentos básicos de Direito da Saúde e gestão e comunicação da informação interpares, mass media e no seio da equipa de saúde (liderança).

A Educação Médica Contínua Pós-Graduada é também uma tarefa essencial. Note-se que a auto-regulação, definida como a capacidade que um corpo de profissionais tem de avaliar a qualidade do seu próprio trabalho é uma responsabilidade-parte de um contrato social, assente no reconhecimento, por parte da sociedade, de que a profissão coloca os interesses de quem serve à frente dos seus próprios interesses e que apenas ela tem conhecimentos técnicos e capacidade para o fazer. Importa consequentemente, não malbaratar, por omissão, esta responsabilidade, este direito. Um modelo integrado e harmonioso de creditação deverá ser procurado, associando o Colégio da Especialidade da OM e a SPDV, potenciando e promovendo eventos e realizações online, bem como publicações nacionais e promovendo o treino adequado e de excelência.

\section{QUAL O MODELO REMUNERATÓRIO PARA OS DERMATOLOGISTAS?}

Temos vindo a assistir ao fim do tradicional vínculo laboral sólido e remuneração fixa dos Médicos, substituído por um modelo remuneratório "à peça" e incentivos pecuniários "à produção". Assistiremos no futuro à imposição da remuneração do acto médico, porém dependente do seu sucesso ("... O pagamento baseado no acto médico vai evoluir no sentido da avaliação dos resultados" - Ministro da Saúde, Dr. Paulo Macedo, Expresso, 17 de Maio de 2015). Tal constitui, importa afirmá-lo, uma radical mudança de paradigma do exercício médico, da tradicionalmente aceite "obrigação de meios" para uma nova "obrigação de resultado". Daqui decorre o inevitável suscitar de questões insanáveis sobre a natureza do acto médico, a quota-parte das responsabilidades do doente, a qualidade da relação médico-doente, o enfoque da prioridade fiduciária, a ética do exercício profissional, a parametrização do "sucesso/insucesso" e os custos de uma medicina hiperdefensiva, entre outras ramificações e consequências que julgo estarem, levianamente, a ser ignoradas ou subvalorizadas. Na mesma linha e neste momento se aceita, acriticamente, como inevitável o princípio do risco partilhado com a Indústria Farmacêutica no que concerne a comparticipação de medicamentos inovadores... Tratam-se claramente de assuntos que devem suscitar discussão e merecer a nossa atenção e apreciação críticas, sempre na defesa do da coerência e harmonia do exercício profissional e no superior interesse do Doente. 


\section{Editorial}

\section{APESAR DE TUDO....}

A Dermatologia é uma Especialidade extraordinariamente apelativa e cativante e os Dermatologistas são, entre a generalidade dos médicos, dos mais afortunados. Assim o confirmam estudos sobre o nível de satisfação e de realização, a taxa de burn out (uma das actuais mais significativas ameaças ao exercício médico) e da felicidade (Medscape Physician Compensation Report, 2011).

No entanto, como a "Happiness is not merely a function of an individual's experience or an individual choice, but is also a property of groups of people" (Fowler J, et al. BMJ, 3 Jan 2009, Vol 38) e os tempos que se avizinham são altamente desafiantes e de elevadíssima complexidade, importa, enquanto grupo profissional, criar uma cultura solidária, de defesa do nosso riquíssimo património ético e técnico-científico, enquanto Médicos e Dermatologistas.

Uma cultura que, defendendo o núcleo da nossa marca identitária como Dermatologistas, preserve os princípios fundacionais do exercício médico, em particular a obrigação fiduciária face ao doente, a autonomia, a justiça e, sobretudo, o princípio do primado do bem-estar do Doente.

"O Princípio do bem-estar do Doente inclui o conceito de que as forças de Mercado, as pressões da Sociedade e as exigências Administrativas não devem comprometer esse Princípio"

Sem conflitos de interesse/No conflict of interest

\section{Rui Tavares Bello}

Assistente Hospitalar de Dermatologia e Venereologia/

Consultant of Dermatology and Venereology

Unidade de Dermatologia do Hospital dos Lusíadas,

Lisboa, Portugal

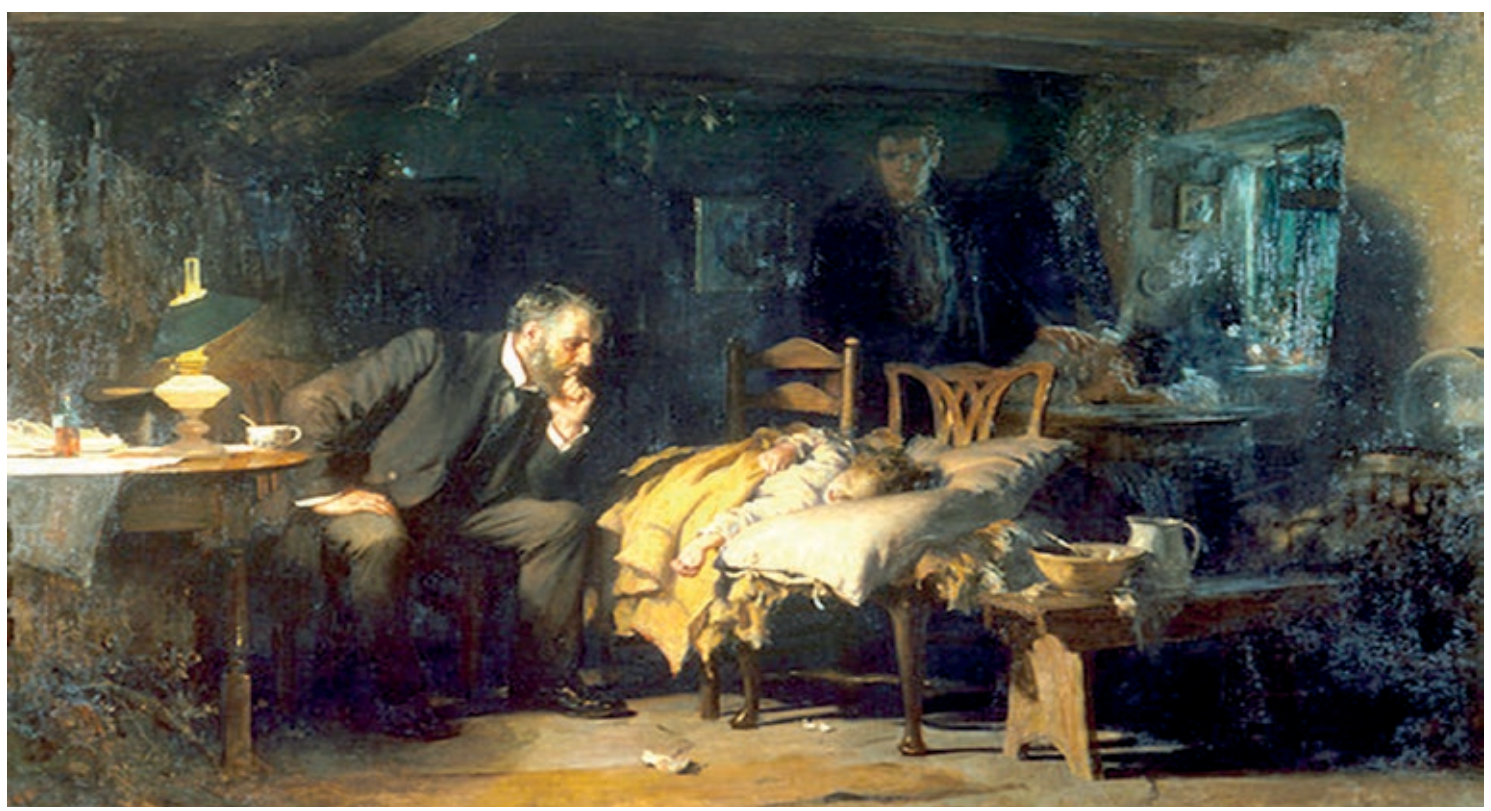

